\title{
Efeito de dietas contendo plasma sanguíneo desidratado sobre características microbiológicas, imunológicas e histológicas de leitões leves ao desmame
}

\author{
[Effect of spray-dried plasma diets on microbiological, immunological and histological parameters \\ of light weight weaned pigs]
}

\author{
D.B. Dalto ${ }^{1}$, D.F. Gavioli ${ }^{1}$, E.R. Oliveira ${ }^{1}$, R.A.M. Silva ${ }^{1}$, M.A. Tarsitano ${ }^{1}$, \\ Á.H.S. Altmann ${ }^{2}$, D.B. Braz ${ }^{3}$, R.K.T. Kobayashi ${ }^{4}$, E.J. Venâncio ${ }^{4}$, \\ A.M. Bridi ${ }^{4}$, A.P.F.R.L. Bracarense ${ }^{4}$, C.A. Silva ${ }^{4}$ \\ ${ }^{1}$ Aluno de pós-graduação - Universidade Estadual de Londrina -UEL - Londrina, PR \\ ${ }^{2}$ Aluno de graduação - Universidade Estadual de Londrina - Londrina, PR \\ ${ }^{3}$ M. Cassab Comércio e Indústria Ltda - São Paulo, SP \\ ${ }^{4}$ Universidade Estadual de Londrina - Londrina, PR
}

\begin{abstract}
RESUMO
Foram avaliados os efeitos do plasma sanguíneo desidratado (PSD) sobre desempenho, perfil imunológico, histológico, microbiológico e peso de órgãos de leitões leves, desmamados aos 21 dias de idade. Foram utilizados 24 leitões, com idade média inicial de 21 dias, em delineamento experimental completamente ao acaso. Os tratamentos foram: T1 - animais pesados ao desmame, sem suplementação com PSD; T2 - animais leves ao desmame, suplementados com 10g/animal/dia de PSD; T3 - animais leves ao desmame, suplementados com 20g/animal/dia de PSD; T4 - animais leves ao desmame, sem suplementação com PSD. A adição de $20 \mathrm{~g}$ de PSD na dieta melhorou o ganho diário de peso, aumentou o peso $(\mathrm{g} / \mathrm{kg})$ do baço e o título de IgA no soro entre 21 e 31 dias de idade. A inclusão de $10 \mathrm{~g}$ de PSD aumentou o comprimento e a largura do linfonodo ileocólico. A inclusão de PSD traz benefícios aos leitões nos primeiros 10 dias pós-desmame, atuando principalmente nos órgãos linfoides e na mucosa intestinal.
\end{abstract}

Palavras-chave: suíno, plasma sanguíneo desidratado, intestino delgado, imunoglobulinas, E.coli

\begin{abstract}
The aim of this experiment was to evaluate the effects of spray-dried plasma (SDP) on the growth performance, immunological, histological and microbiological profile and weight of organs of light weight weaned pigs. The trial was done using 24 pigs with an initial mean age of 21 days in a completely randomized experimental design. The treatments were: T1 - heavy weight weaned pigs, without SDP supplementation; T2 - light weight weaned pigs, supplemented with 10g/animal/day of SDP; T3 - light weight weaned pigs, supplemented with 20g/animal/day of SDP; T4 - light weight weaned pigs, without SDP supplementation. The inclusion of $20 \mathrm{~g}$ of SDP in the diet improved the weight gain, spleen weight $(\mathrm{g} / \mathrm{kg})$ and serum IgA title between 21 and 31 days of age. The inclusion of $10 \mathrm{~g}$ of SDP in the diet improved the length and width of the ileocolic lymph node. In the first 10 days after weaning, SDP improved the development of lymphoid organs and the protection of the intestinal mucosa.
\end{abstract}

Keywords: swine, spray dried plasma, small intestine, immunoglobulins, E. coli

Recebido em 23 de maio de 2011

Aceito em 30 de maio de 2012

E-mail: danyelbd@hotmail.com 


\section{INTRODUÇÃO}

No desmame, o leitão passa por um grande distresse, com repercussões negativas no consumo de ração, no desenvolvimento intestinal e na adaptação à dieta inicial, aumentando a suscetibilidade a problemas entéricos, infecções e diarreias (Pluske et al., 1997).

As alterações intestinais que ocorrem no pósdesmame incluem mudanças na morfologia das vilosidades, criptas e enzimas da borda em escova, tendo sido demonstradas implicações com patógenos entéricos (Escherichia coli e rotavírus) (Pluske et al., 1997). Com o intuito de minimizar essas alterações, vários produtos têm sido incorporados à ração de leitões recémdesmamados. O plasma sanguíneo desidratado (PSD) é um produto com alta palatabilidade, com níveis elevados de aminoácidos e possui imunoglobulinas que podem reduzir a ação de patógenos intestinais, e tem sido utilizado como ingrediente na ração de leitões em fase de creche. Dentre as propriedades relacionadas ao PSD relata-se a redução na expressão de citocinas próinflamatórias (IL-1, IL-6 e TNF-a) no tecido intestinal (Touchette et al., 2002) e a infiltração de células inflamatórias na mucosa intestinal (Jiang et al., 2000).

Segundo Van Dijk et al. (2001), além da alta palatabilidade, os efeitos positivos, provavelmente, envolvem a atividade das glicoproteínas que reforçam a proteção contra $E$. coli e das imunoglobulinas adquiridas por meio do plasma. Segundo Pierce (2005), tanto a palatabilidade quanto os demais efeitos benéficos do PSD são relacionados aos altos níveis de IgG. É provável que a IgG previna a adesão de patógenos, como a $E$. coli, no epitélio intestinal. Além disso, o PSD melhora o desempenho ao incrementar a imunocompetência do animal pelas imunoglobulinas presentes e reduzir a exposição do sistema imune aos antígenos, levando à menor produção de citocinas próinflamatórias e ao aumento do consumo de ração (Dritz et al., 1996). A utilização de PSD de origem suína tem apresentado melhores resultados do que o PSD de origem bovina, sugerindo um efeito específico de imunoglobulinas.
Assim, o objetivo deste trabalho foi avaliar o desempenho, o perfil microbiológico, histológico e imunológico de leitões desmamados leves, alimentados com ração contendo plasma sanguíneo desidratado.

\section{MATERIAL E MÉTODOS}

Foram utilizados 24 leitões da linhagem PenArLan, sendo 16 machos castrados e oito fêmeas. A média de idade no início do experimento foi de 21 dias. Segundo o peso inicial, os animais foram divididos em dois grupos, um com peso inicial entre 4,5 e $5,5 \mathrm{~kg}-$ animais leves ao desmame, e outro com peso inicial entre 5,6 e $6,5 \mathrm{~kg}$ - animais pesados ao desmame. Os animais foram alojados em baias de alvenaria e piso ripado com $3 \mathrm{~m}^{2}$. Em cada baia foram alojados dois animais, um macho castrado e uma fêmea, que receberam água e ração à vontade.

Os animais foram submetidos a um dos seguintes tratamentos $(\mathrm{T})$ experimentais durante 10 dias: T1 - animais pesados, não suplementados com PSD; T2 - animais leves, suplementados com 10g/animal/dia de PSD; T3 - animais leves, suplementados com 20 g/animal/dia de PSD; T4 - animais leves, não suplementados com PSD. As dietas experimentais foram formuladas para a fase pré-inicial I, de 21 a 30 dias de idade. As rações experimentais foram analisadas segundo as metodologias propostas pela Association of Official Analytical Chemists, AOAC (1984), sendo os ingredientes, a composição percentual e os valores analisados encontrados na Tab. 1.

O suplemento proteico, vitamínico e mineral utilizado na ração pré-inicial I (PS 400) apresentava na sua formulação soro de leite, glúten de milho, proteína texturizada de soja, levedura de cana, milho pré-gelatinizado, açúcar e lactose. O PSD comercial continha as seguintes especificações: plasma sanguíneo suíno em pó (98,2\%), vitamina E e DL-metionina, apresentando $77,7 \%$ de proteína bruta, $18.000 \mathrm{mg}$ de metionina e $5 \mathrm{mg}$ de vitamina E, sendo seu fornecimento feito diretamente no cocho, três vezes ao dia. 
Tabela 1. Composição percentual, química e energética da ração experimental usada para leitões

\begin{tabular}{|c|c|}
\hline Ingrediente $(\%)$ & $\begin{array}{l}\text { Pré- inicial I } \\
\text { (PS 400) }\end{array}$ \\
\hline Milho & 43 \\
\hline Farelo de soja & 17 \\
\hline Suplemento suíno fases & 40 \\
\hline Total & 100 \\
\hline \multicolumn{2}{|l|}{ Valores analisados } \\
\hline Proteína bruta $(\%)$ & 19,73 \\
\hline Extrato etéreo (\%) & 2,94 \\
\hline Fibra bruta $(\%)$ & 2,15 \\
\hline Matéria mineral (\%) & 4,38 \\
\hline Cálcio (\%) & 0,63 \\
\hline Fósforo total (\%) & 0,56 \\
\hline Energia metab. (kcal/kg) & 3.296 \\
\hline Lisina total $(\%)$ & 1,41 \\
\hline Metionina total $(\%)$ & 0,50 \\
\hline \multicolumn{2}{|c|}{ 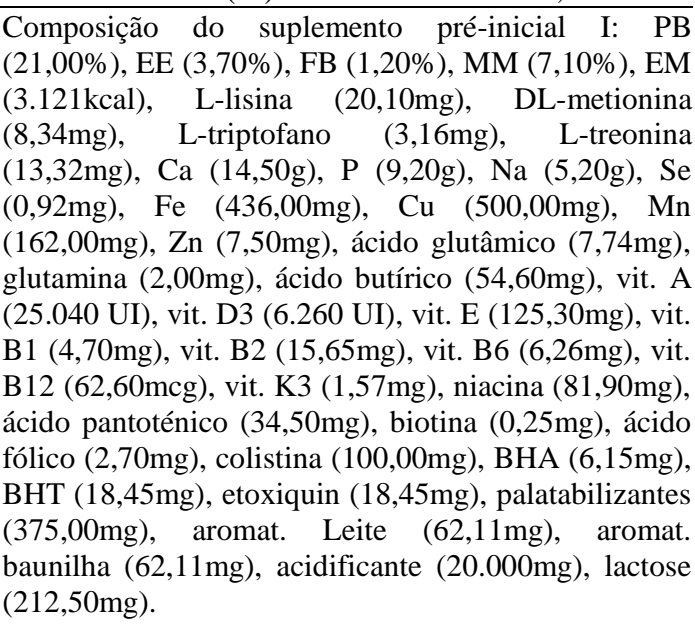 } \\
\hline
\end{tabular}

Para avaliação de desempenho, os animais foram pesados nos dias zero e 10 - dia inicial e final do período experimental, quando foram computados: peso final (PF), consumo diário de ração (CDR), ganho diário de peso (GDP) e conversão alimentar (CA). O delineamento experimental foi o completamente ao acaso, com quatro tratamentos e três repetições por tratamento (três baias com dois leitões). Cada baia, composta por dois animais, foi definida como uma unidade experimental.

Ao final do tratamento, os animais foram abatidos após concussão cerebral seguida de exsanguinação. O projeto foi aprovado pelo Comitê de Ética em Experimentação Animal institucional (processo 194/2009).
Amostras de fezes foram colhidas imediatamente após o abate para a pesquisa de Escherichia coli e Lactobacillus sp. Aproximadamente $10 \mathrm{~g}$ do conteúdo do intestino delgado foram colhidos em frasco estéril e mantidos em refrigeração até o seu processamento, que não ultrapassou duas horas. As amostras foram submetidas à diluição seriada em solução salina $0,85 \%$. A diluição $10^{-1}$ ( $1 \mathrm{~mL}$ da amostra com $9 \mathrm{~mL}$ de salina) foi homogeneizada em vortex por 30s. As demais diluições, até $10^{-6}$, foram homogeneizadas por 10 segundos. Uma alíquota de $100 \mu \mathrm{L}$ de cada diluição foi semeada por espalhamento em superfície em ágar MacConkey e ágar Rogosa, para contagem de Escherichia coli e Lactobacillus sp., respectivamente. $\mathrm{O}$ ágar MacConkey foi incubado em aerobiose, a $37^{\circ} \mathrm{C}$, por 18 a $24 \mathrm{~h}$. O ágar Rogosa foi incubado a $37^{\circ} \mathrm{C}$ por 18 a $24 \mathrm{~h}$, a $5 \% \mathrm{CO}_{2}$ (Pierce, 2007). As colônias crescidas em MacConkey com suspeita de $E$. coli - colônias rosas com morfologia típica - foram semeadas em Triple Sugar Iron Agar (TSI), SIM Mediun - meio de cultura que detecta a produção de $\mathrm{H}_{2} \mathrm{~S}$, indol e motilidade, fenil, citrato e vermelho de metila (VM) para confirmação - e, então, contadas. As colônias grandes claras, de bacilos Gram positivos, crescidas em ágar Rogosa, foram contadas segundo Franklin (2002).

Amostras de sangue e fezes foram colhidas para se avaliar a concentração de $\operatorname{IgG}, \operatorname{IgM}, \operatorname{Ig}$ A no soro e IgA e IgM nas fezes. O sangue foi colhido por venipunção da veia jugular em tubo não heparinizado no início (dia zero) e no final do experimento (dia 10).

As amostras de fezes foram colhidas após o abate e diluídas inicialmente 1:8 em PBS 1X, homogeneizadas em vórtex e centrifugadas a $1500 \mathrm{~g}$ por dois minutos para obtenção do sobrenadante. Posteriormente, as amostras de fezes e soros foram diluídas 1:20 e 1:100 em PBS 1X-glicerina $20 \%$ e armazenadas a $-20^{\circ} \mathrm{C}$ até o momento do processamento. As concentrações de $\operatorname{IgG}$, IgA e IgM foram determinadas pelo sistema ELISA Quantification Set (Bethyl-USA), seguindo as recomendações do fabricante. Para a determinação das concentrações de $\operatorname{IgG}$, $\operatorname{Ig} \mathrm{A}$ e $\operatorname{IgM}$ no soro, as amostras foram diluídas a 1:200.000, 1:1000 e 1:10.000, respectivamente, enquanto os sobrenadantes das fezes foram diluídos a 1:50 e 
1:200, para a quantificação de $\operatorname{IgA}$ e IgM. Os valores de absorbância, obtidos a 450nm, foram analisados pelo programa Curve Expert 1.3.

Após o abate, o conteúdo intestinal foi removido, e o intestino delgado, o ceco e o baço pesados. $\mathrm{O}$ comprimento e a largura dos linfonodos ileocólicos também foram mensurados.

Fragmentos de duodeno, jejuno e íleo foram colhidos e fixados em solução de formalina tamponada a $10 \%$ por 24 horas, sendo posteriormente transferidos para solução de álcool $70 \%$. As amostras foram submetidas ao processamento histológico de rotina, e cortes de $5 \mu \mathrm{m}$ de espessura foram corados pelo método de hematoxilina/eosina. Foi realizada a contagem do número médio de linfócitos na lâmina própria em todos os segmentos do intestino. Para tanto, utilizou-se objetiva de imersão (100x), sendo contados 20 campos em cada lâmina.

A avaliação morfométrica foi realizada em 30 vilosidades e criptas por lâmina, utilizando-se objetiva de 10x em microscópio óptico Zeizz Axioskop. A altura, a espessura das vilosidades e a profundidade das criptas foram mensuradas com o auxílio do programa Motic Image Plus 2.0. A taxa vilosidade:cripta foi calculada dividindo-se a altura da vilosidade pela profundidade da cripta.
O delineamento experimental para as avaliações microbiológica, imunológica e histológica foi o completamente ao acaso, com quatro tratamentos e seis repetições por tratamento. Cada animal foi definido como uma unidade experimental. Os dados relativos aos tratamentos foram submetidos à análise de variância e à comparação de médias pelo teste Tukey utilizando-se o programa SAEG (Sistema..., 1997).

\section{RESULTADOS E DISCUSSÃO}

Os resultados para as características de desempenho zootécnico estão demonstrados na Tab. 2. A diferença significativa verificada para o peso inicial provém do desenho experimental que determinava uma estratificação dos pesos dos leitões. Para o parâmetro peso final, foi observado melhor desempenho para os animais pesados e para os leves tratados com $10 \mathrm{~g}$ e 20g/dia de PSD na ração. Considerando-se que os animais leves iniciaram o experimento, em média, um quilo mais leves em relação aos animais pesados (tratamento 1), concluiu-se que houve uma recuperação desses leitões pela suplementação de PSD. Entretanto, a inclusão de $10 \mathrm{~g}$ e de $20 \mathrm{~g}$ de PSD por dia não determinou resultados estatisticamente diferentes entre si.

Tabela 2. Médias e desvios das características de desempenho de leitões pesados e leves, no período de 21 a 31 dias de idade

\begin{tabular}{|c|c|c|c|c|c|c|}
\hline \multirow{2}{*}{ Variável } & \multicolumn{4}{|c|}{ Tratamento (peso inicial dos leitões/ oferta diária de PSD) } & \multirow{2}{*}{$\mathrm{P}<$} & \multirow{2}{*}{$\mathrm{CV} \%$} \\
\hline & Pesado/0g & Leve/10g & Leve/20g & Leve/0g & & \\
\hline \multicolumn{7}{|l|}{ Período I } \\
\hline $\mathrm{PI}(\mathrm{kg})$ & $5,73 \pm 0,252 \mathbf{a}$ & $4,75 \pm 0,229 \mathbf{b}$ & $4,73 \pm 0,284 \mathbf{b}$ & $4,75 \pm 0200 \mathbf{b}$ & 0,002 & 4,87 \\
\hline $\mathrm{PF}(\mathrm{kg})$ & $7,01 \pm 0,393 \mathbf{a}$ & $6,22 \pm 0,651 \mathbf{a b}$ & $6,34 \pm 0,496 \mathbf{a b}$ & $5,28 \pm 0,076 \mathbf{b}$ & 0,01 & 7,33 \\
\hline CDR $(g)$ & $223 \pm 76$ & $230 \pm 35$ & $210 \pm 26$ & $153 \pm 58$ & ns & 29,03 \\
\hline GDP (g) & $130 \pm 36 \mathbf{a b}$ & $150 \pm 53 \mathbf{a b}$ & $163 \pm 23 \mathbf{a}$ & $57 \pm 25 \mathbf{b}$ & 0,03 & 21,44 \\
\hline $\mathrm{CA}(\mathrm{g} / \mathrm{g})$ & $1,74 \pm 0,052$ & $1,65 \pm 0,455$ & $1,28 \pm 0,174$ & $3,47 \pm 2,042$ & ns & 51,51 \\
\hline
\end{tabular}

Letras diferentes na linha indicam diferença entre os valores significativa pelo teste Tukey (5\%).

$\mathrm{ns}=$ não significativo $(\mathrm{P}>0,05)$.

$\mathrm{PI}=$ peso médio inicial; $\mathrm{PF}=$ peso médio final $\mathrm{CDR}=$ consumo de ração médio diário; $\mathrm{GDP}$ = ganho de peso médio diário; $\mathrm{CA}=$ conversão alimentar.

Período $\mathrm{I}=21$ a 30 dias de idade.

Os mecanismos pelos quais o PSD promove estas melhorias no desempenho dos animais ainda não estão bem elucidados, contudo acredita-se que estejam relacionados à alta palatabilidade do alimento (Ermer et al., 1994), favorecendo o consumo. Os resultados obtidos, entretanto, diferem dos encontrados por Ermer et al. (1994), visto que não houve diferença ( $\mathrm{P}>0,05)$ para o $\mathrm{CDR}$, demonstrando não ter havido favorecimento para melhora do consumo para os tratamentos com $10 \mathrm{~g}$ e $20 \mathrm{~g}$ de PSD em relação aos demais grupos. Os resultados 
também diferem dos encontrados por Gatnau e Zimmerman (1991), que, oferecendo individualmente dietas com PSD e com leite em pó durante as duas primeiras semanas pósdesmame, observaram que os leitões consumiram $50 \%$ mais ração com PSD em relação às dietas com leite em pó. Butolo et al. (1999) observaram efeito linear significativo para o consumo de ração no período de zero a 14 dias pós-desmame para leitões alimentados com inclusões crescentes de PSD (0, 2,5, 5,0 e 7,5\%).

Para o GDP houve diferença $(\mathrm{P}<0,05)$ a favor do tratamento com suplementação de $20 \mathrm{~g}$ de PSD em relação ao grupo de leitões leves que não receberam o plasma. Gatnau e Zimmerman (1991), ao compararem a inclusão de 5\% de PSD versus uma dieta com $7,5 \%$ de farinha de sangue durante duas semanas pós-desmame, observaram que houve melhor GDP, CDR e CA para o tratamento com plasma. Kats (1994) demonstrou aumento linear do GDP, CDR e melhor CA nos primeiros 14 dias pós-desmame com a inclusão de 2,0, 4,0, 6,0 e 8,0\% de PSD nas dietas. No presente trabalho, as inclusões de PSD representaram 3,5 e 7,0\% do consumo na fase pré-inicial I para o tratamento com $10 \mathrm{~g}$ e $20 \mathrm{~g}$ de oferta de plasma, respectivamente.

Com o intuito de verificar o efeito do PSD sobre algumas características de órgãos relacionados aos sistemas imune e digestório, foram realizadas mensurações dos pesos dos órgãos, absoluto e percentual, em relação ao peso vivo inicial e medidas dos linfonodos ileocólicos. Os resultados dessas avaliações estão demonstrados na Tab. 3.

Tabela 3. Peso absoluto ( $\mathrm{g}$ ) e peso percentual ( $\mathrm{g} / \mathrm{kg}$ de peso vivo) do intestino delgado, ceco e baço e comprimento e largura do linfonodo íleocólico $(\mathrm{cm})$ de leitões pesados e leves aos 31 dias de idade

\begin{tabular}{|c|c|c|c|c|c|c|}
\hline \multirow{2}{*}{ Variável } & \multicolumn{4}{|c|}{ Tratamento (peso inicial dos leitões/ oferta diária de PSD) } & \multirow[t]{2}{*}{$\mathrm{P}<$} & \multirow[t]{2}{*}{$\mathrm{CV} \%$} \\
\hline & Pesado/0g & Leve/10g & Leve/20g & Leve/0g & & \\
\hline \multicolumn{7}{|c|}{ Peso dos órgãos } \\
\hline ID $(g)$ & $330 \pm 40 \mathbf{a}$ & $282 \pm 20 \mathbf{a b}$ & $285 \pm 60 \mathbf{a b}$ & $250 \pm 50 \mathbf{b}$ & 0,03 & 15,67 \\
\hline ID $(\mathrm{g} / \mathrm{kg})$ & $4,75 \pm 0,10$ & $4,60 \pm 0,46$ & $4,50 \pm 0,50$ & $4,77 \pm 0,70$ & ns & 14,22 \\
\hline $\operatorname{Ceco}(\mathrm{g})$ & $18 \pm 4$ & $20 \pm 6$ & $20 \pm 6$ & $22 \pm 10$ & ns & 34,76 \\
\hline Ceco $(\mathrm{g} / \mathrm{kg})$ & $0,28 \pm 0,005$ & $0,33 \pm 0,006$ & $0,30 \pm 0,007$ & $0,41 \pm 0,04$ & ns & 36,74 \\
\hline $\operatorname{Baço~}(\mathrm{g})$ & $13 \pm 5$ & $15 \pm 5$ & $18 \pm 10$ & $12 \pm 4$ & ns & 44,70 \\
\hline $\operatorname{Baço~}(\mathrm{g} / \mathrm{kg})$ & $0,21 \pm 0,002 \mathbf{b}$ & $0,26 \pm 0,005 \mathbf{a b}$ & $0,33 \pm 0,01 \mathbf{a}$ & $0,22 \pm 0,003 \mathbf{b}$ & 0,02 & 31,15 \\
\hline \multicolumn{7}{|c|}{ Medidas do linfonodo ileocólico } \\
\hline $\begin{array}{l}\text { Comprimento } \\
(\mathrm{cm})\end{array}$ & $14,75 \pm 0,96 a$ & $14,50 \pm 0,58 \mathrm{a}$ & $11,75 \pm 2,50 \mathrm{ab}$ & $9,00 \pm 2,00 b$ & 0,001 & 13,56 \\
\hline Largura $(\mathrm{cm})$ & $3,16 \pm 0,75 \mathrm{a}$ & $3,75 \pm 0,96 a$ & $2,00 \pm 0,63 \mathrm{~b}$ & $1,80 \pm 0,45 b$ & 0,001 & 26,81 \\
\hline
\end{tabular}

Letras diferentes na linha indicam diferença significativa entre os valores pelo teste Tukey (5\%).

ns $=$ não significativo $(\mathrm{P}>0,05)$.

ID = intestino delgado.

Os leitões pesados apresentaram peso do intestino delgado significativamente maior do que o grupo de leitões leves e sem PSD. Não houve diferença significativa em relação aos outros grupos e em relação ao peso vivo $(\mathrm{g} / \mathrm{kg}$ de peso vivo). Este resultado entre o peso absoluto para os leitões pesados e os demais pode ser naturalmente atribuído ao maior peso inicial dos animais no começo do teste. Resultados semelhantes foram descritos por Pluske et al. (2003), os quais observaram que o peso do estômago, do intestino delgado, do ceco e do cólon eram maiores em leitões pesados e mais velhos ao desmame. Os autores verificaram que, em valores percentuais ( $\mathrm{g} / \mathrm{kg}$ peso vivo), os leitões leves e mais novos ao desmame possuíam intestino delgado maior, no entanto, com o aumento da idade, essa diferença tornou-se insignificante.

Verificou-se aumento significativo no peso percentual ( $\mathrm{g} / \mathrm{kg}$ de peso vivo) do baço (Tab. 3) no grupo tratado com 20g/dia de PSD (tratamento 3). Este resultado pode ser devido ao maior consumo de proteínas determinado pela adição de PSD na dieta, um ingrediente com $77,7 \%$ de proteína bruta, resultando no consumo total no período, de $217,6 \mathrm{~g}$ de proteína a mais em relação aos tratamentos 1 e 4 . 
Os leitões pesados e leves suplementados com PSD apresentaram valores superiores para as medidas de comprimento e largura dos linfonodos ileocólicos em relação aos animais que não receberam PSD (Tab. 3). Estes resultados sugerem que o PSD contribui para melhorar a imunocompetência dos animais. Em outros estudos utilizando PSD na alimentação de leitões, não foram constatadas diferenças significativas no peso do baço e do intestino (Owusu-Aisedu et al., 2003).

Os efeitos do PSD na morfologia intestinal foram avaliados por meio da morfometria das vilosidades intestinais, da contagem do número de linfócitos na lâmina própria e de placas de Peyer. Não houve diferença significativa entre os grupos em relação ao número de linfócitos e de placas de Peyer (dados não demonstrados). Ao compararem leitões de 14 dias submetidos a dietas com e sem PSD, Jiang et al. (2000) observaram redução na densidade de leucócitos na lâmina própria do intestino nos animais que receberam PSD, sugerindo um efeito supressor na resposta pró-inflamatória local.

Os resultados das medidas de altura e espessura das vilosidades, profundidade das criptas e taxa vilosidade:cripta estão demonstrados na Tab. 4. Em todos os segmentos avaliados observou-se que os animais não suplementados com PSD apresentaram, na maioria dos parâmetros avaliados, valores inferiores aos demais tratamentos, indicando que os leitões suplementados com PSD obtiveram um desenvolvimento intestinal superior aos não suplementados, igualando-se aos animais pesados. Melhora na morfologia intestinal independentemente do consumo de ração e incremento na altura de vilosidades e GPD associados à ingestão de PSD foram descritos em leitões (Torrallardona et al., 2003). No entanto, em outro estudo, não se verificou diferença na morfologia duodenal em leitões aos sete e 14 dias após o desmame tratados com PSD, e aos 28 dias pós-desmame a espessura da parede do duodeno e a profundidade das criptas foram menores nos animais alimentados com PSD (Carlson et al., 2005). Outros autores sugerem que o PSD age atenuando a atrofia das vilosidades do intestino delgado (Jiang et al., 2000) ou mantendo a integridade da mucosa intestinal em animais desafiados oralmente com E. coli $\mathrm{K} 88+$ (Bosi et al., 2004).

Tabela 4. Medidas de altura e espessura das vilosidades, profundidade das criptas e taxa vilosidade:cripta do duodeno, jejuno e íleo de leitões pesados e leves aos 31 dias de idade

\begin{tabular}{|c|c|c|c|c|c|c|}
\hline \multirow{2}{*}{ Variável } & \multicolumn{4}{|c|}{ Tratamento (peso inicial dos leitões/ oferta diária de PSD) } & \multirow{2}{*}{$\mathrm{P}<$} & \multirow{2}{*}{$\mathrm{CV} \%$} \\
\hline & Pesado/0g & Leve $/ 10 \mathrm{~g}$ & Leve $/ 20 \mathrm{~g}$ & Leve/0g & & \\
\hline \multicolumn{7}{|l|}{ Duodeno } \\
\hline Alt.vil. & $308,21 \pm 60,56 \mathbf{a}$ & $277,89 \pm 49,73 \mathbf{a b}$ & $296,87 \pm 73,18 \mathbf{a}$ & $216,87 \pm 35,81 \mathbf{b}$ & 0,05 & 20,56 \\
\hline Espess. Vil. & $138,30 \pm 18,07 \mathbf{a}$ & $133,26 \pm 14,36 \mathbf{a b}$ & $152,56 \pm 19,17 \mathbf{a}$ & $115,57 \pm 13,04 \mathbf{b}$ & 0,01 & 12,12 \\
\hline Prof. criptas & $143,88 \pm 23,35$ & $152,20 \pm 45,40$ & $140,68 \pm 34,11$ & $141,15 \pm 41,92$ & ns & 25,73 \\
\hline $\begin{array}{l}\text { Taxa } \\
\text { vil.:cripta }\end{array}$ & $2,16 \pm 0,40$ & $1,96 \pm 0,65$ & $2,24 \pm 0,88$ & $1,68 \pm 0,71$ & ns & 34,00 \\
\hline \multicolumn{7}{|l|}{ Jejuno } \\
\hline Alt.vil. & $275,26 \pm 80,12$ & $294,08 \pm 93,63$ & $274,30 \pm 90,79$ & $211,29 \pm 63,18$ & ns & 31,32 \\
\hline Espess. vil. & $117,20 \pm 6,41$ & $115,45 \pm 10,23$ & $119,64 \pm 11,85$ & $110,30 \pm 17,13$ & ns & 10,48 \\
\hline Prof. criptas & $163,97 \pm 26,93$ & $167,14 \pm 17,09$ & $146,13 \pm 24,11$ & $166,40 \pm 33,15$ & ns & 16,40 \\
\hline $\begin{array}{l}\text { Taxa } \\
\text { vil.:cripta }\end{array}$ & $1,72 \pm 0,62$ & $1,80 \pm 0,70$ & $1,88 \pm 0,61$ & $1,28 \pm 0,32$ & ns & 34,42 \\
\hline \multicolumn{7}{|l|}{ Íleo } \\
\hline Alt.vil. & $265,86 \pm 31,99 \mathbf{a b}$ & $313,13 \pm 59,83 \mathbf{a}$ & $256,63 \pm 34,60 \mathbf{a b}$ & $240,84 \pm 42,52 \mathbf{b}$ & 0,05 & 16,33 \\
\hline Espess. vil. & $117,25 \pm 7,23$ & $112,58 \pm 7,29$ & $120,10 \pm 9,45$ & $113,30 \pm 6,83$ & 0,05 & 6,63 \\
\hline Prof. criptas & $132,06 \pm 11,43 \mathbf{a b}$ & $164,20 \pm 43,90 \mathbf{a}$ & $122,19 \pm 8,84 \mathbf{b}$ & $136,11 \pm 13,59 \mathbf{a b}$ & $\mathrm{ns}$ & 17,67 \\
\hline $\begin{array}{l}\text { Taxa } \\
\text { vil.:cripta }\end{array}$ & $2,03 \pm 0,32$ & $2,00 \pm 0,55$ & $2,12 \pm 0,43$ & $1,80 \pm 0,47$ & ns & 22,70 \\
\hline
\end{tabular}

Letras diferentes na linha indicam diferença significativa entre os valores pelo teste de Tukey (5\%). $\mathrm{ns}=$ não significativo $(\mathrm{P}>0,05)$.

Alt. vil.=altura das vilosidades; Espess. vil.=espessura das vilosidades; Profund. criptas= profundidades das criptas; Taxa vil.:cripta $=$ taxa entre altura das vilosidades e profundidade das criptas. 
No íleo, observou-se diferença $(\mathrm{P}<0,05)$ na altura das vilosidades com vantagem para o tratamento 2 em relação ao 4 e na profundidade das criptas com maiores valores para o tratamento $2 \mathrm{em}$ relação ao 3. Esta hiperplasia das criptas associada ao aumento das vilosidades é característica do período de recuperação intestinal, que se inicia de quatro a cinco dias após o desmame (Carlson et al., 2005), demonstrando que a adição de PSD na dieta de leitões recém-desmamados promoveu uma recuperação intestinal mais rápida.

Os resultados não apresentaram diferença significativa para a contagem de bactérias Gram negativas, Escherichia coli e Lactobacillus sp. entre os tratamentos, no entanto foram observados coeficientes de variação muito elevados para ambas as contagens.

O efeito do tratamento com PSD sobre os títulos de IgA, IgM e IgG séricas nos leitões foi avaliado (Tab. 5). Observou-se aumento significativo do título de $\operatorname{Ig} \mathrm{A}$ entre os 21 e 31 dias de idade nos animais que receberam suplementação com $20 \mathrm{~g}$ de PSD (tratamento 3), indicando um possível efeito do PSD sobre os títulos de $\operatorname{Ig}$ A sérica.

Tabela 5. Títulos de IgG, IgA e IgM séricas de leitões pesados e leves aos 21 e 31 dias de idade

\begin{tabular}{|c|c|c|c|c|}
\hline \multirow{2}{*}{ Variável } & \multicolumn{4}{|c|}{ Tratamento (peso inicial dos leitões/ oferta diária de PSD) } \\
\hline & Pesado/0g & Leve/10g & Leve/20g & Leve/0g \\
\hline \multicolumn{5}{|l|}{21 dias de idade } \\
\hline $\operatorname{IgG}(\mathrm{mg} / \mathrm{mL})$ & $9,62 \pm 2,42$ & $12,93 \pm 4,11$ & $11,40 \pm 3,42$ & $12,13 \pm 4,36$ \\
\hline $\operatorname{IgA}(\mathrm{mg} / \mathrm{mL})$ & $0,15 \pm 0,11$ & $0,23 \pm 0,15$ & $0,17 \pm 0,04 \mathbf{a}$ & $0,16 \pm 0,05$ \\
\hline $\operatorname{IgM}(\mathrm{mg} / \mathrm{mL})$ & $3,12 \pm 2,45$ & $3,18 \pm 1,28$ & $3,27 \pm 1,04$ & $2,30 \pm 0,67$ \\
\hline \multicolumn{5}{|l|}{31 dias de idade } \\
\hline $\mathrm{IgG}(\mathrm{mg} / \mathrm{mL})$ & $9,47 \pm 3,87$ & $9,41 \pm 1,17$ & $10,02 \pm 3,05$ & $10,78 \pm 3,54$ \\
\hline $\operatorname{IgA}(\mathrm{mg} / \mathrm{mL})$ & $0,18 \pm 0,05$ & $0,31 \pm 0,18$ & $0,24 \pm 0,07 \mathbf{b}$ & $0,16 \pm 0,09$ \\
\hline $\operatorname{IgM}(\mathrm{mg} / \mathrm{mL})$ & $2,38 \pm 1,02$ & $2,85 \pm 0,72$ & $2,42 \pm 0,45$ & $2,50 \pm 0,80$ \\
\hline $\mathrm{P}<$ & $\mathrm{ns}$ & $\mathrm{ns}$ & 0,03 & $\mathrm{~ns}$ \\
\hline
\end{tabular}

Letras diferentes na coluna indicam diferença significativa entre os valores pelo teste de Tukey (5\%). ns $=$ não significativo $(\mathrm{P}>0,05)$.

Não foi observada diferença $(\mathrm{P}>0,05)$ para os títulos de IgG, IgA e IgM séricas entre os tratamentos. Este resultado sugere que a concentração de imunoglobulinas dos leitões pesados, bem como dos leves, foi igual ao desmame, igualdade que se manteve independentemente da suplementação com PSD. Os títulos iniciais semelhantes sugerem que o peso médio inicial não interferiu na imunidade dos leitões. Possivelmente, os animais leves ao nascimento tiveram acesso a quantidades suficientes de colostro e, portanto, desenvolveram boa imunidade passiva, mas por fatores diversos (como hierarquia de tetos, frio, manejo inadequado) tiveram seu desempenho prejudicado. Já os títulos finais semelhantes poderiam ser explicados pela baixa exposição desses animais a patógenos, visto que não houve desafio durante o experimento. Ressalta-se que os efeitos positivos do PSD são mais perceptíveis quando os animais são submetidos a desafios e às condições adversas de manejo, ou seja, a maior resposta provém quanto maior é a exposição aos patógenos (Stahly, 1996). Gatnau e Zimmerman
(1991) demonstraram que a magnitude de resposta ao PSD foi maior em leitões alojados em sistema contínuo em relação ao sistema all-in all-out.

Os títulos de $\operatorname{Ig} \mathrm{A}$ e $\operatorname{IgM}$ fecais também foram avaliados, e os resultados estão dispostos na Tab. 6. Houve diferença $(\mathrm{P}<0,05)$ para os títulos de IgA nas fezes. Segundo Pabst et al. (1988), os órgãos linfoides, em especial as placas de Peyer, têm um papel fundamental no início da resposta imune de mucosa, em particular na produção de IgA, dada a maior presença de células B (precursoras de $\operatorname{IgA}$ ) em relação às células $\mathrm{T}$. Segundo Gaskins (1995), a imunidade ativa do intestino não ocorre antes de quatro-sete semanas de idade, o que sugere que os leitões leves ao desmame, ao receberem uma dieta de qualidade e em ambiente adequado, podem apresentar uma produção de anticorpos de mucosa satisfatória, superando os leitões pesados, como pode ser observado na comparação entre os leitões pesados e os leitões leves que receberam 10 g/animal/dia de PSD. 
Tabela 6. Títulos de $\operatorname{IgA}$ e $\operatorname{IgM}$ fecais de leitões pesados e leves aos 31 dias de idade

\begin{tabular}{lllllll}
\hline \multirow{2}{*}{ Variável } & \multicolumn{2}{l}{ Tratamento (peso inicial dos leitões/oferta diária de PSD) } & P< & \multirow{2}{*}{ CV\% } \\
\cline { 2 - 6 } & Pesado/0g & Leve/10g & Leve/20g & Leve/0g & & \\
\hline IgA $(\mathrm{mg} / \mathrm{mL})$ & $0,003 \pm 0,003 \mathbf{b}$ & $0,012 \pm 0,001 \mathbf{a}$ & $0,005 \pm 0,002 \mathbf{a b}$ & $0,002 \pm 0,001 \mathbf{a b}$ & 0,05 & 42,90 \\
$\mathrm{IgM}(\mathrm{mg} / \mathrm{mL})$ & $0,03 \pm 0,00005$ & $0,08 \pm 0,004$ & $0,05 \pm 0,002$ & $0,06 \pm 0,001$ & ns & 81,39 \\
\hline
\end{tabular}

Letras diferentes na linha indicam diferença significativa entre os valores pelo teste de Tukey (5\%).

$\mathrm{ns}=$ não significativo $(\mathrm{P}>0,05)$.

\section{CONCLUSÕES}

O fornecimento de PSD, nas inclusões de $10 \mathrm{ou}$ 20g/animal/dia, nos primeiros 10 dias pósdesmame, proporciona benefícios ao desenvolvimento dos leitões, com ênfase na maturação de órgãos linfoides e na proteção da mucosa intestinal, garantindo maior ganho de peso aos leitões leves ao desmame.

\section{REFERÊNCIAS}

ASSOCIATION of official analytical chemistsAOAC. Official methods of analysis of the Association of Official Analytical Chemists. 14.ed., p.164, 1984.

BOSI, P.; CASINI, L.; FINAMORE, A. et al. Spraydried plasma improves growth performance and reduces inflammatory status of weaned pigs challenged with enterotoxigenic Escherichia coli K88. J. Anim. Sci., v.82, p.1764-1772, 2004.

BUTOLO, E.A.F.; MIYADA, V.S.; PACKER, I.U.; MENTEN, J.F.M. Uso de plasma suíno desidratado por spray dried na dieta de leitões desmamados precocemente. Rev. Bras. Zootec., v.28, p.326-333, 1999.

CARLSON, M.S.; VERUM, T.L.; TURK, J.R. Effects of yeast extract versus animal plasma in weanling pig diets on growth performance and intestinal morphology. J. Swine Health Prod., v.13, p.204-209, 2005.

DRITZ, S.S.; OWEN, K.Q.; GOODBAND, R.D. et al. Influence of lipopolysaccharide-induced immune challenge and diet complexity on growth performance and acute-phase protein production in segregated early-weaned pigs. J. Anim. Sci., v.74, p.1620-1628, 1996.

ERMER, P.M.; MILLER, P.S.; LEWIS, A.J. Diet preference and meal patterns of weanling pigs offered diets containing either spray-dried porcine plasma or dried skim milk. J. Anim. Sci., v.72, p.1548-1554, 1994.
FRANKLIN, M.A.; MATHEW, A.G.; VICKERS, J.R.; CLIFT, R.A. Characterization of microbial populations and volatile fatty acid concentrations in the jejunum, ileum, and cecum of pigs weaned at $17 \mathrm{vs}$ 24 days of age. J. Anim. Sci., v.80, p.2904-2910, 2002.

GASKINS, H.R.; KELLEY, K.W. Immunology and Neonatal Mortality. In: VARLEY, M.A. The Neonatal Pig. Development and Survival. Wallingford: CAB International, 1995. p.39-56.

GATNAU, R.; ZIMMERMAN, D.R. Spray dried porcine plasma (SDPP) as a source of protein for weanling pigs in two environments. J. Anim. Sci., v.69, p.103, 1991. (abstr.)

JIANG, R.; CHANG, X.; STOLL, B. et al. Dietary plasma protein reduces small intestinal growth and lamina propria cell density in early weaned pigs. $J$. Nutr., v.130, p.21-26, 2000.

KATS, L.J.; NELSSEN, J.L.; TOKACH, M.D. et al. The effect of spray-dried porcine plasma on growth performance in the early-weaned pig. J. Anim. Sci., v.72, p.2075-2081, 1994.

OWUSU-ASIEDU, A.; NYACHOTI, C.M.; BAIDOO, S.K. et al. Response of early-weaned pigs to an enterotoxigenic Escherichia coli $(K 88)$ challenge when fed diets containing spray-dried porcine plasma or pea protein isolate plus egg yolk antibody, zinc oxide, fumaric acid, or antibiotic. Am. Soc. Anim. Sci., v.81, p.1790-1798, 2003.

PABST, R.; GEIST, M.; ROTHKOTTER, H.J.; FRITZ, F.J. Postnatal development and lymphocyte production of jejunal and ileal Peyer's patches in normal and gnotobiotic pigs. Immun., v.64, p.539-544, 1988.

PIERCE, J.L.; CROMWELL, G.L.; LINDEMANN, M.D. et al. Effects of spray-dried animal plasma and immunoglobulins on performance of early weaned pigs. J. Anim. Sci., v.83, p.2876-2885, 2005.

PIERCE, K.M.; CALLAN, J.J.; MCCARTHY, P.; O'DOHERTY, J.V. The interaction between lactose level and crude protein concentration on piglet postweaning performance, nitrogen metabolism, selected faecal microbial populations and faecal volatile fatty acid concentrations. Anim. Feed Sci. Tech., v.132, p.267-282, 2007. 
PLUSKE, J.R.; HAMPSON, D.J.; WILLIAMS, H.R. Factors influencing the structure and function of the small intestine in the weaned pig: A review. Livest. Prod. Sci., v.51, p.215-236, 1997.

PLUSKE, J.R.; KERTON, D.J.; CRANWELL, P.D. et al. Age, sex and weight at weaning influence organ weight and gastrointestinal development of weanling pigs. Austr. J. Agr. Res., v.54, p.515-527, 2003.

SISTEMA de Análises Estatísticas e Genéticas SAEG. Viçosa: UFV, 1997.

STAHLY, T. Influencia de la activacion del sistema immunitario sobre la produtividad y las características nutricionales de dietas para cerdos. In: REBOLLAR, P.G.; MATEOS, G.G.; BEORLEGUI, C.B. (Eds.). Avances en Nutricion e Alimentación Animal., 1996. $96 \mathrm{p}$.
TORRALLARDONA, D.; CONDE, M.R.; BADIOLA, I. et al. Effect of fishmeal replacement with spray-dried animal plasma and colistin on intestinal structure, intestinal morphology, amd performance of weanling pigs challenged with Escherichia coli K99. J. Anim. Sci., v.81, p.12201226, 2003.

TOUCHETTE, K.J.; CARROLL, J.A.; ALLEE, G.L. et al. Effect of spray-dried plasma and lipopolysaccharide exposure weaned pigs: I. Effects on the immune axis of weaned pigs. J. Anim. Sci., v.80, p.494-501, 2002.

VAN DIJK, A.J.; EVERTS, H.; NABUURS, M.J.A. et al. Growth performance of weaned pigs fed spraydried animal plasma: a review. Livest. Prod. Sci., v.68, p.263-274, 2001. 